\title{
STUDY ON SURFACE ROUGHNESS AND MATERIAL REMOVAL RATE (MRR) OF ALUMINIUM 2024 IN ELECTRICAL DISCHARGE MACHINING
}

\author{
T Ramesh Kumar \\ Associate Professor, Bannari Amman Institute of Technology, \\ Sathyamangalam, India \\ T Guruprakash, P Nandha Kumar, R Gokul \\ Student, Bannari Amman Institute of Technology, \\ Sathyamangalam, India
}

\begin{abstract}
Surface Roughness and Material Removal Rate are foremost important factor in Electrical Discharge Machining (EDM). This study is done to see about how different machine parameters affect the Surface Roughness as well MRR. The material used is of Aluminium 2024 which has wide range of applications in Automotive and Aerospace Industry. In Aluminium 2000 series, constitution of Copper is the highest. The main reason for u sing Aluminium is its effective use in many Industry as well its abundance in nature. It can be treated with many other elements and properties can be widely changed to achieve the desirable uses. Copper electrodes are used for machining due its high electric resistance between the metals as well proper current discharge when compared to other electrodes. This work would give a glimpse of how Surface Roughness and MRR vary with Gap Voltage and Pulse On-Time. Peak current is fixed as constant value as they don't play a major role in determining the Surface Roughness and MRR. The above said parameters are varied to the requirement and the readings are noted down. Later MRR, Surface Roughness are measured and the readings are plotted in table. Graphs are plotted from the values obtained and conclusions are made from it. For higher Gap Voltage and optimum Pulse On-Time it showed greater Surface Roughness as well good MRR.
\end{abstract}

Keywords: Aluminium 2024, Copper Electrode, MRR, Surface Roughness

\section{INTRODUCTION}

Electrical Discharge Machining (EDM) is special type of machining process used in special conditions. They can be used to machine compounds in required spaces as well required profiles. EDM or spark machining or spark eroding is used in the manufacturing industry for obtaining the desired shape by using electrical sparks. Removal of metal takes place from a workpiece by a series of rapid current discharge between two electrodes. It is like a battery having two electrodes positive and negative present in an electrolyte.

One of the electrodes is a tool and other one workpiece but instead of electrolyte the dielectric liquid is used also called as EDM liquid. There will no direct contact will be present between electrodes. When the voltage supply is gradually increased simultaneously increase the intensity of electric field volume this becomes more strengthens than dielectric liquid. As the resulting metal is removed from the workpiece. The dielectric liquid is always circulated and allowed to flush near the spark area to avoid overheating and to carry away the removed material. The workpiece is held by using the magnetic champing but for non-magnetic materials support magnetic material is used (1).

\subsection{ALUMINIUM 2024 ALLOY}

Aluminium (Al) is one of the most abundant metal, available third in the earth. It has more than 250 combinations of a different mineral. It is silver-white, non-ferrous, and non-magnetic in boron family in the periodic table. It is Face Cantered Cubic (FCC) crystal structure. It is famous for its low density and corrosionresistant nature. $\mathrm{Al}$ is also famous for its application in aerospace, building structures, Automobiles and Military Vehicles. Here comes the advantage of Aluminium 2024 because Aluminium is already corrosive resistive, Aluminium 2000 series is an alloy of copper as the main alloying element. The typical Aluminium 2024 alloy used in this work is shown in below Figure 1. 


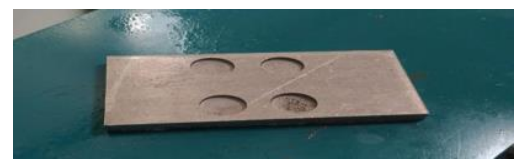

Figure 1. Aluminium 2024 Alloy

Aluminium 2024 has high weldability, easy machinability, fatigue resistance, strength to weight ratio.

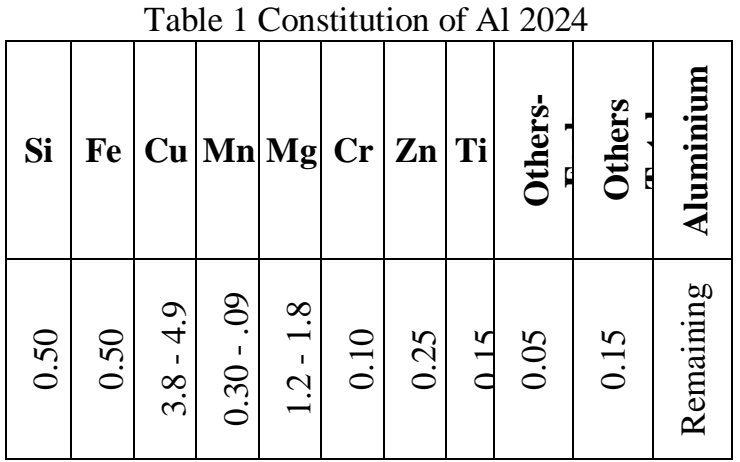

Constitutions of Aluminium 2024 are described in the above Table 1. It can be easily extruded than forged. It requires no heat treating. It has more applications on airplanes especially wings and fuselage structure on applied loads. It is used in Military Combat Vehicle providing higher efficiency at higher altitudes.

\subsection{COPPER ELECTRODE}

Copper Electrode is sulphate coated and polished one. They are alloyed with suitable metals to achieve the desired discharge properties. Copper are primarily chosen due to their effective electric conductance and discharge. Copper electric potential between the Aluminium are also high which makes it perfect for the machining of the Aluminium. Copper Electrode has better wear resistance when compared to other widely used electrodes such as Brass and Graphite. The Surface Finish extruded on the metal surface is of fine texture. In EDM redeposition of metal back to the machined part is also possible; it can simply done by changing the polarity of the material and electrode.

\section{LITERATURE SURVEY}

Sohail Parsana et al, have done a vehicle search algorithm for optimizing machine parameters for EDM machine for different alloys. They have developed mathematical model for the optimization technique on EDM parameter as well analysed results from data obtained during machining and concluded using ANOVA table. The result well stated the how machine parameters played a crucial role in determining the machining process in order to achieve the desired properties [2].

Vikram Singh et al, discussed Wire Electrical Discharge Machining (WEDM) optimization parameter for steel alloy. Mainly concentrated on surface properties and from data obtained from the EDM process were concluded using Taguchi method. This method also helped in forecasting and setting the machine parameters beforehand in achieving the required surface properties [3].

K. Rajkumar et al, have studied on EDM for microwave treated different metal alloys. They concluded that microwave treated alloy was more effective in machining process of alloys as well MRR was faster resulting in good surface finish. Time taken for MRR was quite less when compared non treated one [4].

M.A. Razak et al, have contemplated EDM process for Biodegradable Magnesium alloy. They concluded that EDM reduced craters and cracks as well pulse on-time played a significant role in the process. As the alloy is Biodegradable it finds its application in vast fields and microbial actions on the alloy greatly affects the Magnesium alloy properties [5].

Vikas et al., and Senthil Kumar et al., have introduced optimization of machine parameter for surface roughness. The experiment was processed through Taguchi method and different machine parameters were optimized and they found discharge current played a significant role in it. The experiment value was close to the predicted one $[6,7]$.

Sheemoy kamar Nayak et al, have condensed the idea of multi-objective optimization in stainless steel (Austenitic). The results were concluded using Grey Relational Analysis. MRR and cutting force were using Taguchi design. Dry turning of metal alloy was found to be bit difficult than treated one [8].

Pujari Srinivasa Rao et al, have studied the optimization parameters for MRR, Surface Roughness and White layer for Aluminium alloy. It was concluded that negligence of cutting rate is best for good quality surfaces. The mathematical model has also proven to be justifying the same [9].

Skivkant Tilekar et al, have proven different machine parameter has significant role in machining of Mild Steel and Aluminium using EDM. They used Taguchi method for result conclusion and they stated how MRR and Surface integrity varied for different machine parameter [10].

A.M. Abdul Rani et al, have investigated with use of nano Aluminium have helped in improving the surface quality and MRR in EDM. It also helped in reducing internal cracks as well helped in preventing corrosion. Carbon coating above the surface have helped in improving surface properties [11]. 


\section{International Journal of Engineering Applied Sciences and Technology, 2019 \\ Vol. 4, Issue 7, ISSN No. 2455-2143, Pages 144-148 \\ Published Online November 2019 in IJEAST (http://www.ijeast.com)}

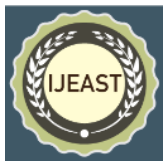

Sarabjeet Singh Sindhu et al, studied and analysed Recast layer of Metal Matrix Composite after machining in EDM. It was evident that recast layer was more in densely packed Metal Matric Composite. The layer heavily depends on internal structure of the Metal Matrix Composite [12].

Based on above Literature Surveys it was found that only few Literatures were available for the study of Surface Roughness and MRR of Aluminium 2024 alloy in EDM. In this study will help in understanding better about these parameters in machining of Aluminium alloy using EDM.

\section{EXPERIEMENTAL PROCEDURE}

EDM Machine is cleaned at first before the operation. The specimen is now placed in the working table which is connected to the positive polarity and the specimen is fixed with help of magnetic specimen holder. Fig 2 shows the typical EDM machine used in this work.

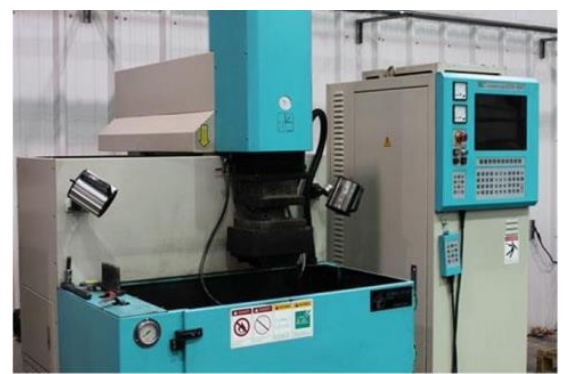

Figure 2 EDM Machine

Then the Dielectric fluid pump is switched on till the fluid tank gets filled till the brim. EDM electrode positions are adjusted according to the requirement of machining to be followed. Peak Current is now set as constant and rest of parameters such as Gap Voltage and Pulse On-time are varied to the desired values. The depth of machining is noted down in the axis and the machining is stopped when the desired value is achieved. EDM operating conditions are mentioned in the Table 2 At initial the weight of the metal is noted down. Later after each machining cycle the metal is removed from the workbench and the weight is noted down. The MRR is calculated with the help of weight before machining to weight after machining. The Surface Roughness is measured with the help of Profilometer. Set all the machine values to zero, drain all the Dielectric fluid and switch off the machine. All the data are now plotted in the table and Graphs are plotted out. From the Graph inference and conclusion are drawn out. This process has to done for each machining cycle and hence machining operation has to be carefully handled out to get more accurate values.
Table 2 Operating conditions of EDM

\begin{tabular}{|l|c|}
\hline Working Conditions & Description \\
\hline Dielectric Fluid & EDM Oil \\
\hline Discharge Current & $1-50 \mathrm{~A}$ \\
\hline Electrode Polarity & Negative \\
\hline Specimen Polarity & Positive \\
\hline Electrode Material & Copper \\
\hline
\end{tabular}

\section{EXPERIMENTAL RESULTS}

The experimental results are obtained in the table 3 . The Peak Current is fixed at 6 amps and the rest Gap Voltage and Pulse On-Time are varied for different set of values. The MRR is calculated from the weight obtained before machining to the weight after machining. Surface Roughness is measured using Profilometer. This process continues after each machining cycle. It was observed that, experimental 6 holds best result for Surface Roughness as well good MRR.

Table 3 Observation Table

\begin{tabular}{|c|c|c|c|c|c|c|}
\hline $\begin{array}{l}\dot{Z} \\
\dot{\sim}\end{array}$ & 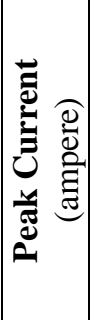 & 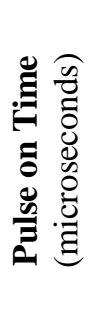 & 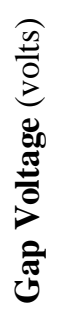 & 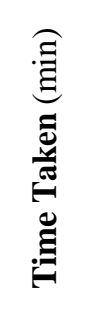 & 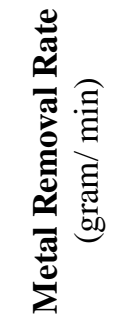 & 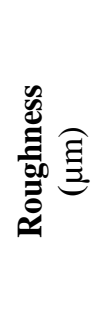 \\
\hline 1 & 6 & 10 & 25 & 16.32 & 0.0439 & 11.34 \\
\hline 2 & 6 & 10 & 50 & 20.23 & 0.0350 & 7.53 \\
\hline 3 & 6 & 10 & 75 & 28.34 & 0.0255 & 5.86 \\
\hline 4 & 6 & 15 & 25 & 10.12 & 0.0477 & 8.96 \\
\hline 5 & 6 & 15 & 50 & 9.56 & 0.0743 & 6.08 \\
\hline 6 & 6 & 15 & 75 & 9.34 & 0.0911 & 4.51 \\
\hline 7 & 6 & 20 & 25 & 11.68 & 0.0640 & 9.11 \\
\hline 8 & 6 & 20 & 50 & 30.24 & 0.0186 & 6.54 \\
\hline 9 & 6 & 20 & 75 & 41.07 & 0.0145 & 7.09 \\
\hline
\end{tabular}

\subsection{SURFACE ROUGHNESS INFERENCE}

Surface Roughness is important parameter in machining operation. In this when Pulse On- Time and Gap Voltage are minimum the Surface Roughness is at its maximum. When Gap Voltage is more and optimum Pulse On-Time is maintained the Surface Roughness is relatively low as because of high spark discharge for low interval of time and maintained Peak Current. The abrupt variation in Surface Roughness is due to the variation in Spark discharge for the interval of time. 


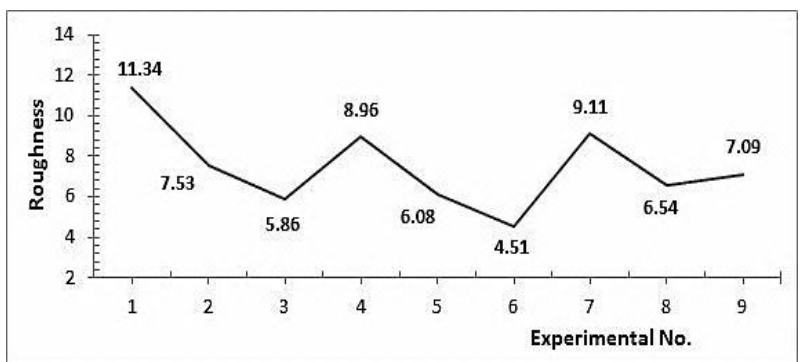

Fig 3 Graph between Surface Roughness Vs Experimental No

\subsection{MRR INFERENCE}

MRR is another important parameter in EDM to optimize the machining parameters to achieve desired MRR. The lowest MRR was observed when high Pulse On-Time and Gap Voltage was set, this is due to less spark discharge per interval of time.

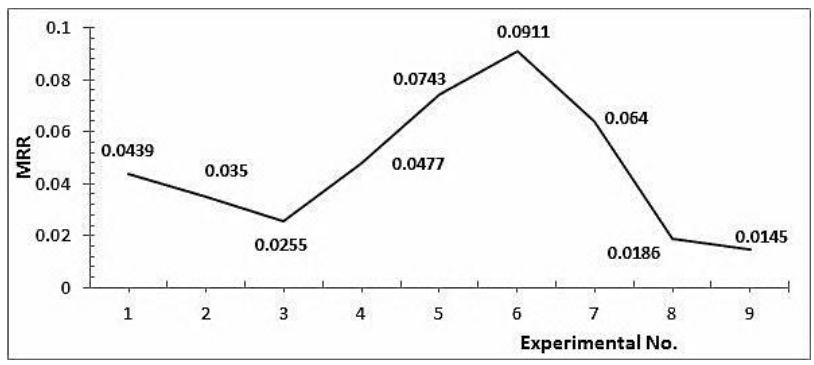

Fig 4. Graph between MRR Vs Experimental No

MRR was high when Gap Voltage was high with optimum Pulse On-Time was set. Change MRR across is due the variation in spark discharge for the interval of time.

\section{CONCLUSION}

Thus, a study on Surface Roughness and MRR was performed on Al 2024 alloy using EDM and the results were obtained. Various conclusions were obtained from the graph for different machine parameters. For higher Gap Voltage and optimum Pulse On-Time it showed greater Surface Roughness as well good MRR and Peak Current did not a vital role as it was fixed to a constant value [13]. With the help of the above conclusion machine parameters can accordingly be set in order to achieve the desired output and even the parameters can be better optimized.

\section{REFERENCES}

[1] Elman C. Jameson (2001), Electrical Discharge Machining, Society of Manufacturing Engineers, ISBN 087263521X.

[2] Sohail Parsana, Nishil Radadia, Mohak Sheth, Nisarg Sheth, Vimal Savsani (2018), Machining parameter optimization for EDM machining of Mg-RE-Zn-Zr alloy using multi-objective Passing
Vehicle Search algorithm, Vol 18 (Pg 799-817).

[3] Vikram Singh, S.K. Pradhan (2014), Optimization of WEDM parameters using Taguchi technique and Response Surface Methodology in machining of AISI D2 Steel, Global Congress on Manufacturing and Management, Vol 97 (Pg 1597-1608).

[4] K RajKumar, S Santosh, A Gnanavelbabu (2014), Effect of Electrical discharge machining parameters on microwave heat treated Aluminium-boron carbide-Graphite composites, Global Congress on Manufacturing and Management, Vol 97 (Pg 1543-1550).

[5] M.A. Razak, A.M. Abdul-Rani, S. kamal, S.R. Pedapati (2014), Electrical Discharge Machining on Biodegradable AZ31 Magnesium Alloy using Taguchi method, International Conference on Process Engineering and Advanced Materials, Vol 148 (Pg 916-922).

[6] Vikas, Apurba kumar Roy, Kaushik Kumar (2014), Effect and Optimization of various Machine Process Parameters on the Surface Roughness in EDM for an EN41 Material using Grey-Taguchi, International Conference on Materials Processing and Characteristics, Vol 148 (Pg 916-922).

[7] K L Senthil Kumar and T Ramesh Kumar (2015), An Integrated Approach To Optimize Parameters In Electrochemical Machining Process, International Journal of Applied Engineering Research, Vol. 10 (Pg 8297-8306).

[8] Shreemoy Kumar Nayak, Jatin Kumar Patro, Shailesh Dewangan, Soumya Gangopadhyay (2014), Multi-Objective Optimization Parameters During Dry Turning of AISI 304 Austenitic Stainless Steel Using Grey Relational Analysis, International Conference on Materials Processing and Characteristics, Vol 2104 (Pg 701-708).

[9] Pujari Srinivasa Rao, Koona Ramji, Beela Sathyanarayana (2014), Experimental Investigation and Optimization of Wire EDM Parameters for Surface Roughness, MRR and White Layer in Machining of Aluminium Alloy, International Conference on Advances in Manufacturing and Materials Engineering, Vol 5 (Pg 2197-2206).

[10] Shivkant Tilekar, Sankha Shurva Das, P.K. Patowari (2014), Process Parameter Optimization of Wire EDM on Aluminium and Mild Steel by using Taguchi Method, International Conference on Advances in Manufacturing and Materials Engineering, Vol 5 (Pg 2577-2584).

[11] A.M. Abdul-Rani, A.M. Nanimina, T.L. Ginta, M.A. Razak (2017), Machined Surface Quality in Nano Aluminium Mixed Electrical Discharge Machining, International Conference in Material Processing and Manufacturing, Vol 7 (Pg 510517).

[12] Sabarjeet Singh Sidhu, Preetkanwal Singh Bains 
(2107), Study of the Recast Layer of Particulate Reinforced Metal Matrix Composite machined by EDM, International Conference of Materials Processing and Characterization, Vol 4 (Pg 32433251).

[13] G.V. Chaitanya Bharath Kumar, M. Madhu Sudhana Prasad, S. kumar Swamy (2017), Effect of Graphite and Copper Tools on MRR and Surface Roughness by using Mineral Oil while machining INCONEL600 on EDM, International Journal of Engineering Applied Sciences and Technology, Vol 2 (Pg 93-110)

[14]T. Senthilvelan, P.Balasubramanian (2014), Optimization of Machining Parameters in EDM Using Cast and Sintered Copper Electrodes, Procedia Material Science, Vol 6 (Pg 1292-1302).

[15] Samesh S. Habib (2009), Study of the parameters in Electrical Discharge Machining through response Surface Methodology Approach, Applied Mathematical Modelling, Vol 33 (Pg 4397-4407). 